\title{
AVALIAÇÃO DA SAZONALIDADE DA PRODUÇÃO DE SERAPILHEIRA NUMA FLORESTA ESTACIONAL DECIDUAL NO MUNICÍPIO DE SANTA MARIA-RS ${ }^{1}$
}

\author{
Flávia Gizele König ${ }^{2}$, Mauro Valdir Schumacher ${ }^{3}$, Eleandro José Brun ${ }^{4}$ Irene Seling ${ }^{5}$
}

\begin{abstract}
RESUMO - Durante o período de um ano, foram avaliadas a quantidade de serapilheira depositada e a sazonalidade de sua queda em um ecossistema de Floresta Estacional Decidual, próximo ao município de Santa Maria-RS. Para o estudo foram utilizados 30 coletores de metal de formato circular, com $50 \mathrm{~cm}$ de diâmetro, distribuídos de maneira sistemática em seis parcelas de formato retangular, medindo 18 x $20 \mathrm{~m}$, em área com características ambientais semelhantes. O material depositado foi coletado mensalmente, separado em diferentes frações, seco e pesado. A queda de serapilheira foi de $9,2 \mathrm{Mg} / \mathrm{ha} / \mathrm{ano}$, apresentando a seguinte composição: $67,8 \%$ de folhas, $19,3 \%$ de galhos finos e 12,9\% de miscelânea (flores, frutos, sementes, outros materiais vegetais). As maiores produções de serapilheira ocorreram entre julho e setembro, no período de inverno, e as menores entre outubro e abril, na primavera e no verão. A deposição de serapilheira apresentou correlações negativas com a temperatura.
\end{abstract}

Palavras-chave: Floresta Estacional Decidual, serapilheira e sustentabilidade.

\section{EVALUATION OF THE SEASONAL VARIATION OF LITTER PRODUCTION IN A SEASONAL DECIDUOUS FOREST IN SANTA MARIA, RS}

\begin{abstract}
The amount of litter produced and its seasonal fall were estimated during the period of one year, in a Seasonal Deciduous Forest ecosystem next to Santa Maria, RS. Thirty round-shaped metal collectors $(50 \mathrm{~cm}$ diameter) were used, systematically distributed in 6 rectangular plots $(10 \mathrm{~m} \times 20 \mathrm{~m})$ presenting similar environmental characteristics. The material deposited was collected monthly, separated into different fractions, dried and weighed. Litter production was $9.2 \mathrm{Mg} /$ halyear, presenting the following composition: $67.8 \%$ of leaves, $19.3 \%$ of fine branches and $12.9 \%$ of miscellany (flowers, fruit, seeds and other plant materials). The greatest amounts of litter production occurred between the months of July and September, in the winter, and the smallest productions between October and April, in the spring and summer. The devolution of litter presented negative correlations with the temperature.
\end{abstract}

Key words: $\quad$ Seasonal Deciduous Forest, litter and sustainability.

\section{INTRODUÇÃO}

Devido ao uso extensivo da madeira, consideráveis áreas são desmatadas todo ano para atender à demanda. Portanto, tem-se uma economia que é baseada somente na exploração, sem o mínimo planejamento de uso do recurso. Desta maneira, a cobertura florestal do Rio Grande do Sul, que no início da colonização européia cobria pelo menos a terça parte do Estado, hoje representa apenas 5,6\%, de acordo com o "Inventário Florestal

1 Recebido para publicação em 4.6.2001.

Aceito para publicação em 20.6.2002.

Trabalho realizado com o auxílio da FAPERGS/RS.

2 Acadêmicos do Curso de Engenharia Florestal da Universidade Federal de Santa Maria - UFSM, 97105-900 Santa Maria-RS, <flaviagizele@yahoo.com.br>; ${ }^{3}$ Prof. Dr. nat. techn. do Departamento de Ciências Florestais da UFSM, Bolsista do CNPq, <schuma@ ccr.ufsm.br>; ${ }^{4}$ Eng. Florestal-Mestrando do Programa de Pós-graduação em Engenharia Florestal da UFSM; ${ }^{5}$ Prof ${ }^{a}$. Dr. Visitante, do Departamento de Ciências Florestais da UFSM. 
Nacional - Rio Grande do Sul" (Brasil, 1983). Aliado a esse fato, o que se observa nas florestas remanescentes é um mosaico de diversos estádios sucessionais, com diferentes graus de perturbação.

De acordo com Cunha (1997), a Floresta Estacional Decidual é uma das formações florestais mais importantes do Estado, em termos de localização geográfica, área ocupada e importância histórico-cultural, sendo poucas as informações que se tem sobre este ecossistema, principalmente relacionadas à produção de serapilheira e à ciclagem de nutrientes.

Conforme Schumacher \& Hoppe (1998), no interior de uma floresta a serapilheira depositada sobre o solo desempenha papel fundamental na manutenção das condições ideais para o processo de infiltração de água. $\mathrm{O}$ escoamento superficial em áreas florestais é muito pequeno, devido à grande infiltração e retenção de água pela serapilheira, variando conforme sua espessura.

A produção de serapilheira e a devolução de nutrientes em ecossistemas florestais constituem a via mais importante do ciclo biogeoquímico (relação dos nutrientes no esquema solo-planta-solo). Esse ciclo caracterizase, no primeiro estádio, pela absorção de nutrientes pelas raízes e por sua distribuição pelas diferentes partes da planta, sendo a taxa de absorção de nutrientes maior no período em que as árvores se encontram em estádio juvenil, o que corresponde ao período de maior produtividade dentro do processo de sucessão (Kimmins, 1987). Após esse período, os nutrientes são transferidos novamente para o solo, pela deposição de serapilheira, lixiviação de folhas, ramos e troncos e pela ação da chuva, além do trabalho da fauna herbívora e da dispersão de frutos e sementes (Poggiani \& Schumacher, 2000).

Objetivou-se com o presente estudo avaliar a sazonalidade de deposição e a produção anual de serapilheira em uma Floresta Estacional Decidual em Santa MariaRS, visando fazer inferências sobre a dinâmica da serapilheira na referida floresta.

\section{MATERIAL E MÉTODOS}

\subsection{Caracterização da Área de Estudo}

O estudo foi realizado em uma área conhecida como "Chácara do Morro", 3- Distrito de Camobi, município de Santa Maria-RS.

O município de Santa Maria encontra-se a aproximadamente $90 \mathrm{~m}$ de altitude, entre os paralelos $29^{\circ} 43^{\prime} 57^{\prime}$ '

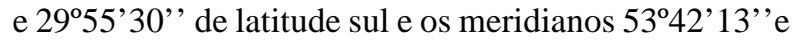
$53^{\circ} 48^{\prime} 02^{\prime \prime}$ ' de longitude oeste de Greenwich.

O clima é do tipo Cfa, subtropical úmido, segundo a classificação de Köppen (Moreno, 1961), caracterizado por temperatura média anual entre 17,9 e $19,2^{\circ} \mathrm{C}$, sendo a temperatura média do mês mais quente superior a $22^{\circ} \mathrm{C}$. A precipitação média anual varia entre $1.400 \mathrm{e} 1.760 \mathrm{~mm}$, sendo bem distribuída ao longo do ano. Os dados meteorológicos usados para as correlações com os resultados deste trabalho foram obtidos na Estação Meteorológica

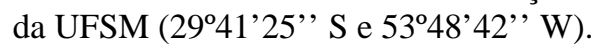

Pela classificação de Reitz et al. (1988), a área de pesquisa localiza-se na Depressão Central do Estado. Essa região compreende duas topografias bem distintas: terrenos mais baixos ou levemente ondulados e os contrafortes da Serra Geral. Nessa última havia densas florestas. Longhi et al. (2000) procederam à caracterização fitossociológica da mesma área objeto deste estudo. Os autores destacaram a ocorrência de 64 espécies arbóreas e arbustivas de 54 gêneros e 31 famílias. As espécies com maior valor de importância foram cabriúva (Myrocarpus frondosus Allemão), camboatá-vermelho (Cupania vernalis Cambess.), canela-guaicá (Ocotea puberula Nees), guajuvira (Patagonula americana L.), chá-de-bugre (Casearia sylvestris Sw.), açoita-cavalo (Luehea divaricata Mart.), timbaúva (Enterolobium contortisiliquum (Vell.) Morong) e canela-de-veado (Helietta apiculata Benth.). Na regeneração, as espécies com maior densidade de indivíduos foram pau-de-ervilha (Trichilia elegans A. Juss.), canela-preta (Nectandra megapotamica (Spreng.) Mez), laranjeira-do-mato (Actinostemom concolor Müll. Arg.), pimentinha (Piper gaudichaudianun Kunth), camboatá-vermelho (Cupania vernalis Cambess.), viuvinha (Hybanthus bigibbosus Hassl.), canela-vermelha (Aiouea saligna Meisn.) e angico-vermelho (Parapiptadenia rígida (Benth.) Brenan).

De acordo com as características do local, o solo pertence à Unidade de Mapeamento Charrua, apresentando Neossolos Litólicos eutróficos, textura média, relevo montanhoso e substrato basalto, sendo solos pouco desenvolvidos, rasos e moderadamente drenados. Nessa unidade de mapeamento observam-se, em geral, afloramentos de rochas (Brasil, 1973).

O local onde foi realizado este estudo sofreu fortes perturbações, podendo ter sido utilizado para fins agrícolas, em razão do amontoamento de pedras e de 
sinais de antigos terraceamentos. Com o abandono da atividade agrícola houve auto-recuperação, formandose ali uma vegetação secundária, que hoje possui idade entre 35 e 40 anos. Porém, nos últimos anos, com o grande crescimento populacional de Santa Maria, essa área próxima à cidade passou a ser visitada por pessoas e por animais domésticos. Essas visitas foram muito prejudiciais à área, causando danos como destruição de subbosque, derrubada de árvores e arvoretas, lixo etc. Com o posterior fechamento da área para realização de pesquisas, esta se encontra em processo de recuperação.

\subsection{Metodologia}

Para o estudo, foram demarcadas seis parcelas de formato retangular, medindo 18 x 20 m, em uma área com características ambientais semelhantes. Em cada parcela foram instalados cinco coletores, distribuídos um próximo a cada canto da parcela e o último, no centro.

A amostragem da serapilheira ocorreu por meio de coletores circulares compostos de um aro de metal com 0,50 m de diâmetro, fixado no solo através de duas hastes de metal soldadas ao arco, ficando o coletor a $0,5 \mathrm{~m}$ do solo. Nesta estrutura metálica prendeu-se uma tela de sombrite ( $2 \mathrm{~mm}$ ) com $50 \mathrm{~cm}$ de comprimento, completando a estrutura do coletor.

O material foi coletado mensalmente, entre julho de 1999 e junho de 2000. Após cada coleta, a serapilheira foi levada ao Laboratório de Ecologia Florestal (Departamento de Ciências Florestais/UFSM), onde foi segregada nas frações folhas, galhos finos ( $<1 \mathrm{~cm}$ de diâmetro) e miscelânea. Em seguida, o material foi seco em estufa a $75^{\circ} \mathrm{C}$, por 48 horas, e pesado em balança de precisão (0,01 g), determinando-se assim a massa das amostras, que foram extrapoladas para a estimativa de massa seca por hectare.

\section{RESULTADOS E DISCUSSÃO}

\subsection{Produção Anual e Sazonalidade da Devolução de Serapilheira}

A produção de serapilheira durante o ano de estudo foi de $9,2 \mathrm{Mg} / \mathrm{ha} / \mathrm{ano}$, sendo formada por $67,8 \%$ de folhas, $19,3 \%$ por galhos finos ( $<1 \mathrm{~cm}$ de diâmetro) e $12,9 \%$ de miscelânea (flores, frutos, sementes, outros materiais vegetais).
Cunha (1997), estudando três fases sucessionais de Floresta Estacional Decidual na região central do Rio Grande do Sul, relatou valor semelhante ao deste estudo, ou seja, 9,5 Mg/ha/ano para uma floresta secundária de mais de 30 anos de idade, formação um tanto mais recente que a deste estudo, que apresenta idade em torno de 40 anos. Porém, para uma capoeira (13 anos) e um capoeirão (19 anos) o autor obteve valores inferiores, iguais a 5,7 e 7,9 Mg/ha/ano, respectivamente.

Cunha et al. (1993), estudando uma área próxima à do presente trabalho, relataram valor igual a 7,7 Mg/ha/ano de produção de serapilheira anual. Backes et al. (2000), estudando uma Floresta Ombrófila Mista em São Francisco de Paula-RS, relataram uma produção de serapilheira de 7,2 Mg/ha/ano em floresta com araucária (Araucaria angustifolia) e 7,9 Mg/ha/ano, para um povoamento de araucária com idade de 50 anos.

Brun et al. (1999) estudaram três fases sucessionais denominadas de capoeirão (27 anos), floresta secundária (50 anos) e floresta madura (+ de 100 anos), de uma Floresta Estacional Decidual em Santa Tereza-RS, relatando uma produção de serapilheira de 6,5, 7,4 e $9,7 \mathrm{Mg} / \mathrm{ha} /$ ano, respectivamente.

Comparando os resultados encontrados neste estudo com outros trabalhos realizados também em Floresta Estacional Decidual, pode-se dizer que são valores que variam de médio a alto. Tal fato talvez se deva ao grau de perturbação da floresta estudada, onde ela, como estratégia de recuperação, esteja investindo grande aporte de energia na produção de material foliar e reprodutivo, depositando também maior conteúdo de serapilheira. Segundo Waring \& Schlesinger (1985), nos estádios iniciais do desenvolvimento das florestas grande parte dos carboidratos é utilizada para a formação de raízes novas e de brotos e folhas. Brown \& Lugo (1990) também destacaram que em florestas secundárias a alocação de energia para produção de folhedo é priorizada até o momento em que o dossel se fecha; a partir de então a produção de serapilheira e a ciclagem de nutrientes irão estabilizar-se, sendo, após esse processo, priorizado o crescimento em área basal e em volume de madeira.

Com relação às variáveis meteorológicas, pode-se observar no Quadro 1 que a produção de serapilheira esteve mais correlacionada com a temperatura média mensal, comportando-se de forma inversa a ela $(r=-0,54)$. Não foi obtido um coeficiente de correlação com a mesma significância para a variável precipitação.

R. Árvore, Viçosa-MG, v.26, n.4, p.429-435, 2002 
Quadro 1 - Coeficiente de correlação de PEARSON, para as variáveis comparadas Table 1 - Pearson Correlation coefficient for the variables compared

\begin{tabular}{|l|c|c|c|c|}
\hline \multicolumn{1}{|c|}{ Variável Climática } & Folhas & Galhos Finos & Miscelânea & Serapilheira \\
\hline Precipitação $(\mathrm{mm})$ & $-0,19$ & $-0,23$ & 0,09 & $-0,18$ \\
\hline Temperatura $\left({ }^{\circ} \mathrm{C}\right)$ & $-0,52 *$ & $-0,42 *$ & $-0,38$ & $-0,54 *$ \\
\hline
\end{tabular}

* Correlações significativas a 5\% de probabilidade de erro.

As Figuras 1 e 2 apresentam a sazonalidade da deposição de serapilheira comparada com a precipitação e com a temperatura média mensal.

As maiores produções de serapilheira ocorreram entre os meses de julho e setembro, e também no mês de maio. Os pontos de coincidência entre as maiores deposições de serapilheira e as altas precipitações não foram significativos, uma vez que houve altas produções em meses de alta e baixa precipitação, devido ao comportamento sazonal da queda de serapilheira, de difícil afirmação para a precipitação. Tal fato também é evidenciado pela baixa correlação entre estas duas variáveis (Quadro 1). Cunha et al. (1993) relataram aspecto um tanto contrário, em que as maiores produções de serapilheira ocorreram quando as precipitações foram abundantes e a temperatura estava em elevação.

Um padrão sazonal de deposição de serapilheira já foi observado por outros autores (Cunha et al., 1993; Cunha, 1997; Brun et al., 1999) em florestas do Sul do Brasil. Nessas regiões, a ausência de extremos climáticos, aliada à diversidade florística, permite que essas florestas produzam serapilheira durante todo o período do ano, mesmo que haja maior derrubada após o inverno, antes que ocorram as maiores taxas de aparecimento de brotos novos, que renovam a folhagem da vegetação.

Aspecto um tanto diferenciado pode ser notado neste trabalho, cujos maiores níveis de deposição foram antecipados em relação ao encontrado pelos autores citados. Encontrou-se uma maior deposição de serapilheira já em julho, prolongando-se somente até setembro, e não até o verão (Figura 2).

Observou-se que duas das espécies com maior valor de importância, a timbaúva (Enterolobium contortisiliquum (Vell.) Morong) e o açoita-cavalo (Luehea divaricata Mart.), com deciduidade mais concentrada no período de inverno, dominaram a deposição de serapilheira neste período de maior queda, influindo decisivamente na curva de deposição.
Cunha (1997) realizou a separação do folhedo coletado por espécie. $\mathrm{O}$ autor relatou que em comunidades mais jovens, onde a produção de serapilheira é dominada por espécies pioneiras, as folhas apresentam um tempo médio de vida relativamente pequeno, em comparação ao das folhas de espécies de sub-bosque. $\mathrm{O}$ autor também relatou que diferentes espécies apresentam picos de produção de folhedo em meses distintos, os quais, nas espécies avaliadas, variaram desde o período de inverno até o fim do verão.

O grande pico de devolução de serapilheira do mês de setembro é associado à fenologia predominante das espécies que compõem a floresta em estudo, a qual, por não ser muito diversificada, obedece a um padrão quase único quanto à derrubada das folhas no final do período de seca fisiológica, provocada pelo frio, para a retomada do crescimento com a nova brotação no início da primavera, ou seja, principalmente no mês de setembro.

As menores produções ocorreram entre os meses de outubro e abril, quando houve apenas pequenas oscilações, que não interferiram no padrão de deposição. No início desse período, pode-se perceber grandes aberturas no dossel da floresta, pela pequena quantidade de folhas existentes, cuja maioria do material foliar era constituída de brotos novos.

A deposição mensal de serapilheira apresentou elevados desvios em torno da média. Conforme Poggiani \& Monteiro Jr. (1990), tal fato reflete a grande heterogeneidade do dossel da floresta, composta por diferentes situações de regeneração.

\subsection{Fracionamento da Serapilheira}

As folhas foram a fração determinante no padrão sazonal da deposição de serapilheira, com correlação de $\mathrm{r}=0,99$. A produção anual da fração folhas foi de $6,2 \mathrm{Mg} / \mathrm{ha} / \mathrm{ano}$, equivalendo a $68 \%$ da serapilheira total. 


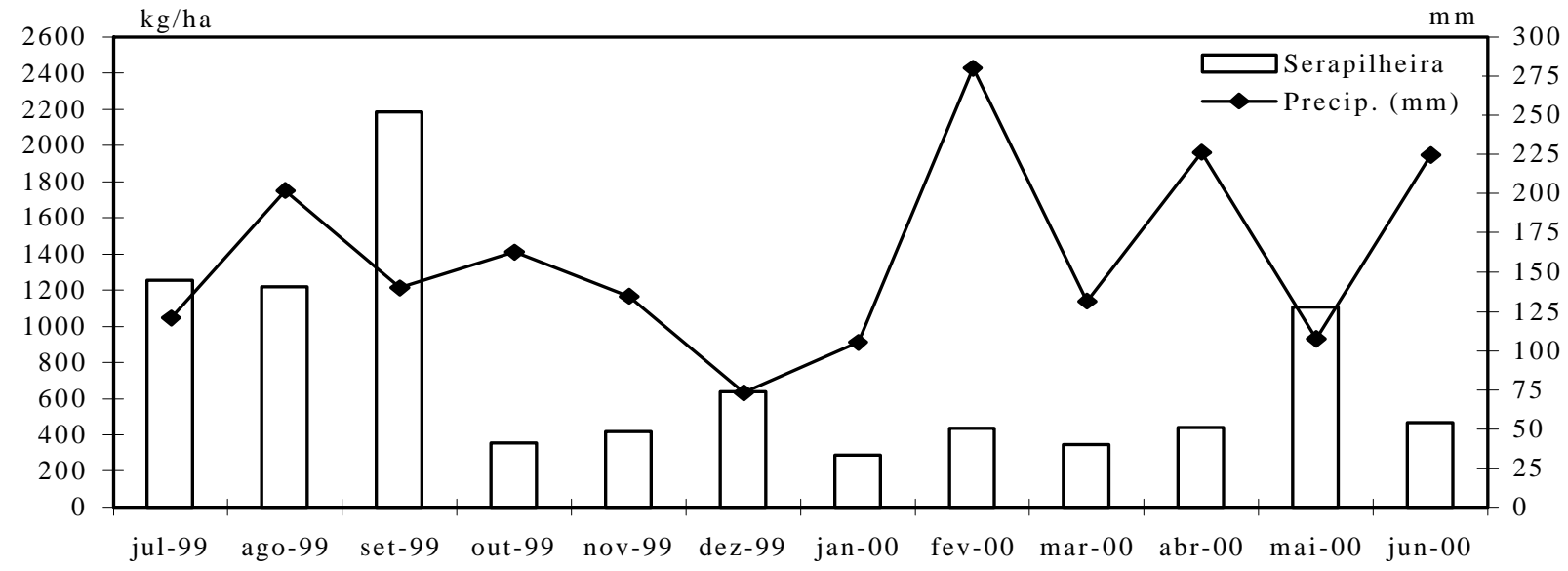

Figura 1 - Produção média mensal de serapilheira $(\mathrm{kg} / \mathrm{ha})$ e precipitação média mensal $(\mathrm{mm})$. Figure 1 - Litter monthly average production $(\mathrm{kg} / \mathrm{ha}$ ) and monthly average precipitation ( $\mathrm{mm}$ ).

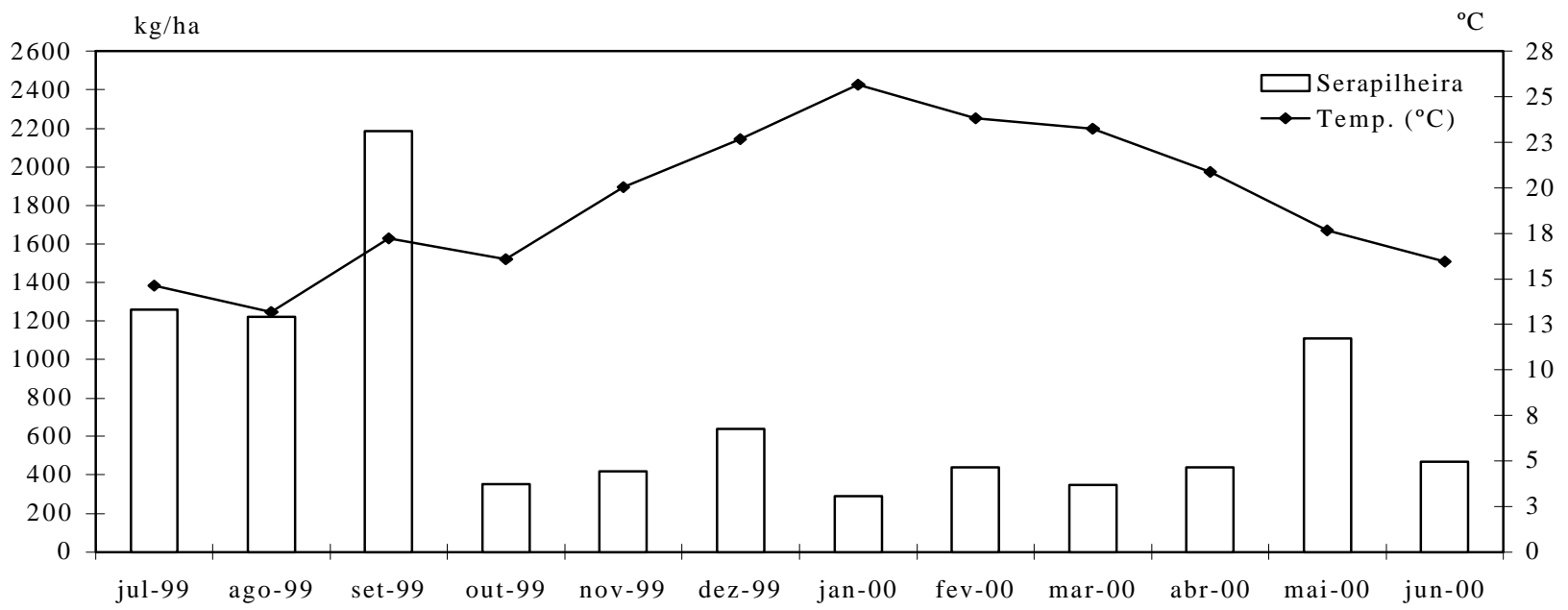

Figura 2 - Produção média mensal de serapilheira $(\mathrm{kg} / \mathrm{ha})$ e temperatura média mensal $\left({ }^{\circ} \mathrm{C}\right)$. Figure 2 - Litter monthly average production $(\mathrm{kg} / \mathrm{ha})$ and monthly average temperature $\left({ }^{\circ} \mathrm{C}\right)$.

A produção média anual de folhas, neste trabalho, esteve dentro do intervalo estabelecido em estudo em nível mundial, realizado por Bray \& Ghoran (1964), porém ocorreram variações em sua contribuição porcentual para a serapilheira total durante o ano, de $54,6 \%$ em fevereiro a $84,5 \%$ em junho. Esses autores concluíram que, de modo geral, nas diferentes zonas macroecológicas as serapilheiras amostradas em diferentes florestas do mundo são compostas de $60-80 \%$ por folhas, de $1-15 \%$ por frutos, de $12-15 \%$ por ramos e de $1-15 \%$ por cascas de árvores.

Pode-se perceber que a quantidade de folhas produzida em Florestas Estacionais Deciduais encontra-se próxima ao ponto médio do intervalo estabelecido pelos citados autores. Cunha (1997) relatou porcentagens entre 65 e $73 \%$ para os três estádios sucessionais. Brun et al. (1999) verificaram valores que variaram entre 65 e $71 \%$ para os estádios sucessionais de capoeirão, floresta secundária e floresta madura de uma Floresta Estacional Decidual em Santa Tereza-RS. Cunha et al. (1993) relataram que a fração folhas foi responsável por $66 \%$ do total de serapilheira.

As variações mensais na deposição das diferentes frações formadoras da serapilheira podem ser verificadas na Figura 3.

R. Árvore, Viçosa-MG, v.26, n.4, p.429-435, 2002 


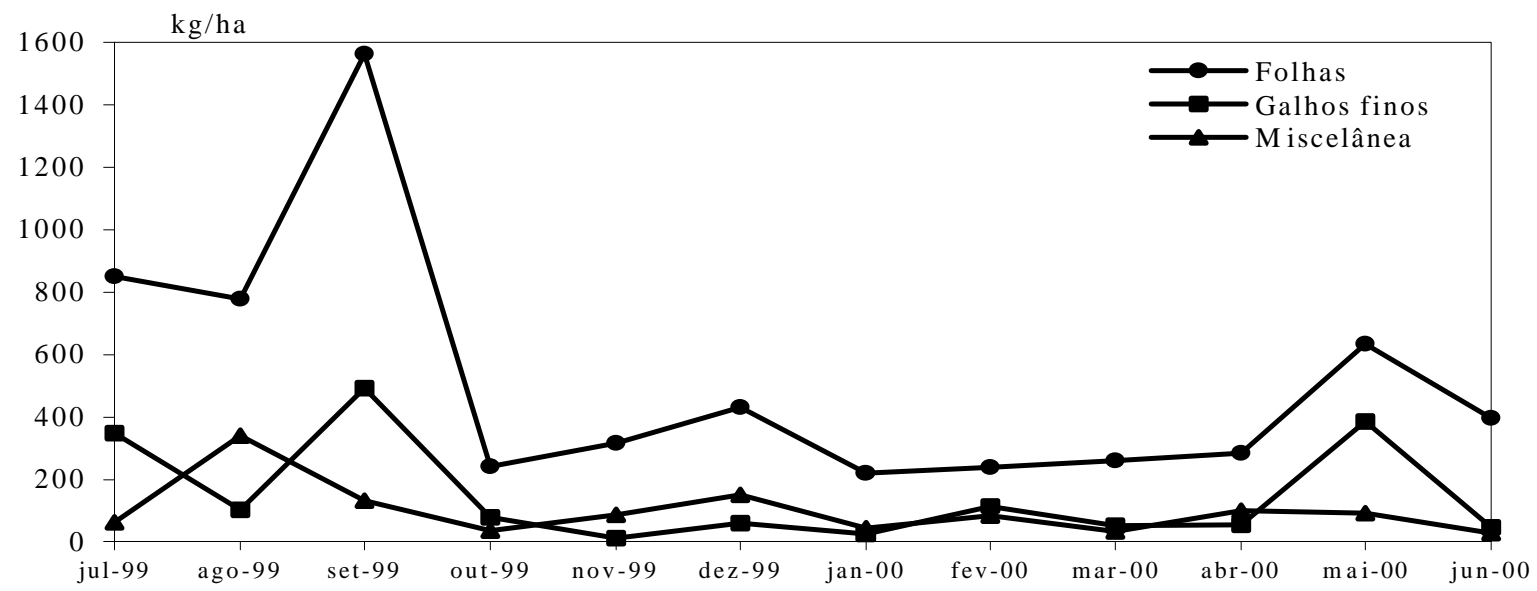

Figura 3 - Variação da produção de serapilheira de diferentes frações, em kg/ha, para uma Floresta Estacional Decidual. Santa Maria-RS.

Figure 3 -Litter production variation in the different fractions, in kg / ha, for a Seasonal Deciduous Forest in Santa Maria, RS.

A fração galhos finos também acompanhou o padrão sazonal de deposição da serapilheira, seguindo o mesmo desenvolvimento da fração folhas, contribuindo com $19,3 \%$ da serapilheira total. A correlação entre a produção de galhos e a serapilheira também foi alta $(\mathrm{r}=0,88)$, assim como para a fração galhos e folhas $(r=0,85)$. Porém, as variações na queda de galhos foram mais acentuadas, variando a porcentagem desta fração em relação à serapilheira total, de $34,6 \%$ em maio até 3,3\% em novembro. Tais quantidades amplamente variáveis de queda de galhos podem ser atribuídas à ocorrência de fenômenos climáticos adversos, como tempestades com ventos anormais. Também, esse fato pode ser explicado pelo menor tamanho da área amostral (coletor), talvez não muito apropriado para a coleta dessa fração.

A fração miscelânea contribui com $12,9 \%$ da serapilheira, apresentando uma produção de $1,2 \mathrm{Mg} / \mathrm{ha} /$ ano. Essa fração demonstrou também altas variações em sua quantidade nos diferentes meses, variando de forma mais diferenciada em relação à queda de serapilheira $(\mathrm{r}=0,45)$. Foram observados valores que variaram entre 4,9 e $28 \%$. Acredita-se que valores como esse máximo ocorrido estejam relacionados com a sucessão da floresta, uma vez que um grande número de timbaúvas (Enterolobium contortisiliquum) encontrava-se em fase de senescência, apresentando uma grande derrubada de detritos diversos, como espessas cascas do tronco.

Outro fator importante está relacionado ao período de floração das espécies que compõem a comunidade.
Desta forma pode-se verificar na Figura 3 que a queda da fração miscelânea segue padrões diferentes das demais frações, sendo, provavelmente, influenciada pelos períodos de floração das espécies mais abundantes na área, as quais, por ocasião da derrubada de suas flores e frutos, incrementam a fração miscelânea com material dessa ordem.

\section{CONCLUSÕES}

a) $\mathrm{O}$ valor de produção de serapilheira encontrado neste estudo $(9,2 \mathrm{Mg} / \mathrm{ha} / \mathrm{ano})$ pode ser classificado entre médio e alto, comparando-se com outros trabalhos realizados em Floresta Estacional Decidual. Dentre os fatores associados a este fato destaca-se $o$ alto grau de perturbação da floresta, que investe maior aporte de energia na produção de serapilheira, como estratégia de recuperação.

b) Os maiores picos de deposição da serapilheira ocorreram entre os meses de julho e setembro, quando se inicia um período de elevação da temperatura. Tal estratégia é característica das florestas estacionais deciduais do Sul do Brasil, onde uma estagnação do crescimento provocada pelo inverno faz com que ocorra a eliminação da folhagem senescente, visando o novo período de crescimento, que se inicia com a primavera, com o aparecimento de folhagem nova.

c) A fração folhas foi determinante na composição da serapilheira, com $67,8 \%$ de participação. Tal fração 
apresenta o mesmo padrão sazonal de deposição da serapilheira total, sendo por isto relatada por muitos autores como suficiente para explicar a produção de serapilheira em florestas. A fração galhos contribuiu com 19,3\% da serapilheira total e a fração miscelânea, com 12,9\%. Esta última fração apresenta sazonalidade de deposição um tanto diferenciada da fração folhas, fato relacionado às características fenológicas das espécies mais importantes da floresta.

\section{REFERÊNCIAS BIBLIOGRÁFICAS}

BACKES, A.; FERNANDES, A. V.; ZENI, D. J. Produção de folhedo em uma floresta com Araucaria angustifolia no sul do Brasil. Revistas de Pesquisas, Botânicas, n. 50, p. $97-117,2000$.

BRASIL. Ministério da Agricultura. IBDF. Inventário Florestal Nacional: Floresta Nativa, Rio Grande do Sul. Brasília: 1983.

BRAY, J. R.; GORHAM, E. Litter production in forests of the world. Advances in Ecological Research, v. 2, p. 101157, 1964.

BROWN, S.; LUGO, A. E. Tropical secondary forest. Journal of Tropical Ecology, v. 6, p. 1-32. 1990.

BRUN, E.J.; VACCARO, S.; SCHUMACHER, M.V. Produção de serapilheira e devolução de nutrientes em três fases sucessionais de uma Floresta Estacional Decidual no município de Santa Tereza-RS. In: SIMPÓSIO SOBRE FERTILIZAÇÃO E NUTRIÇÃO FLORESTAL, 1999, Piracicaba. Anais.... Piracicaba: IPEF-ESALQ/USP. 1999. p. 348-364.

CUNHA, G. C. Aspectos da Ciclagem de nutrientes em diferentes fases sucessionais de uma Floresta Estacional do Rio Grande do Sul. Piracicaba: Escola Superior de Agricultura "Luiz de Queiroz", 1997. 86 p. Dissertação (Mestrado em Engenharia Florestal) - Escola Superior de Agricultura "Luiz de Queiroz", 1997.
CUNHA, G. C. et al. Dinâmica nutricional em floresta estacional decidual com ênfase aos minerais provenientes da deposição da serapilheira. Ciência Florestal, v. 3, n. 1, p. 35-64, 1993.

KIMMINS, J. P. Forest ecology. New York: Collier Macmillan Canada, 1987; São Paulo: Ed. UNESP, 1993. $184 \mathrm{p}$.

LONGHI, S. J. et al. Aspectos fitossociológicos de fragmento de floresta estacional decidual, Santa Maria, RS. Ciência Florestal, v. 10, n. 2, p. 59-74. 2000.

MOREnO, J. A. Clima do Rio Grande do Sul. Porto Alegre: Secretaria da Agricultura, 1961. 73 p.

POGGIANI, F.; SCHUMACHER, M. V. Ciclagem de nutrientes em Florestas Nativas. In: GONÇALVES, J. L. M.; BENEDETTI, V. (Eds.). Nutrição e fertilização florestal. Piracicaba: IPEF/Escola Superior de Agricultura "Luiz de Queiroz", 2000. 427 p.

POGGIANI, F; MONTEIRO JUNIOR, E. S. Deposição de folhedo e retorno de nutrientes ao solo numa floresta estacional semidecídua, em Piracicaba (estado de São Paulo). In: CONGRESSO FLORESTAL BRASILEIRO, 6. , 1992, Campos do Jordão. Anais ... Campos do Jordão: 1990. p. 596-602.

REITZ, R.; KLEIN, R. M.; REIS, A. Projeto madeira do Rio Grande do Sul. Porto Alegre: Secretaria da Agricultura e Abastecimento, 1988. 525 p.

SCHUMACHER, M. V.; HOPPE, J. M. A floresta e a água. Porto Alegre: Pallotti, 1998. 70 p.

WARING, R. H.; SCHLESINGER, W. H. Forest ecosystems: concepts and management. London: Academic Press, 1985. 375 p. 